\title{
Vancomycin Use in a Paediatric Intensive Care Unit of a Tertiary Care Hospital
}

\author{
Kannan Sridharan ${ }^{1}$ (D) Amal Al-Daylami ${ }^{2,3} \cdot$ Reema Ajjawi $^{3} \cdot$ Husain AM Al Ajooz $^{3}$
}

Published online: 20 June 2019

C) Springer Nature Switzerland AG 2019

\begin{abstract}
Background Vancomycin is one of the commonly used anti-microbial drugs in intensive care units (ICUs). Guidelines recommend maintaining therapeutic trough levels of vancomycin $(10-20 \mathrm{mg} / \mathrm{L})$. The success of achieving the recommended therapeutic concentration of vancomycin is influenced by several factors, and this is even more complex in children, particularly those admitted in the ICU. Hence, we carried out the present study in children admitted in the ICU who were administered vancomycin.

Methods We carried out a chart review of children admitted in the paediatric ICU unit of a tertiary care hospital over a period of 3 years. Information on their demographic factors, diagnoses, duration of hospital stay, vancomycin treatment (dose, frequency and time of administration) and concomitant drugs, and vancomycin trough levels were retrieved. Descriptive statistics were used for representing the demographic factors, and multivariable logistic regression analyses were carried out to assess the determining factors.

Results One-hundred and two children were identified, of whom 13 had renal dysfunction. Two-hundred and fifty-two vancomycin trough levels were available, of which only $25 \%$ were observed in the recommended range (10-20 mg/L) amongst patients without any renal dysfunction and $22 \%$ amongst patients with renal dysfunction. Vancomycin was administered intravenously at an average [standard deviation (SD)] dose (mg/dose) of 13 (3.9) mostly either thrice or four times daily. Even in patients receiving vancomycin as a definitive therapy, only $40.9 \%$ achieved the recommended trough levels. Lower trough levels were associated with an increased risk of mortality. Nearly $4 \%$ of the levels were above $20 \mathrm{mg} / \mathrm{L}$ (toxic range). Seven children were suspected to have acute kidney injury (AKI) during the course of therapy where the cumulative vancomycin dose and mortality rate was higher. Only one serum vancomycin level during augmented renal clearance was observed in the recommended range. All the patients received at least one concomitant drug that either had nephrotoxic potential or predominant renal elimination, and use of a greater number of such drugs was associated with an increased risk of AKI.

Conclusion The current vancomycin dosing strategy is ineffective in achieving therapeutic trough levels in children admitted to the ICU. Sub-therapeutic vancomycin trough levels significantly increase the risk of mortality.
\end{abstract}

\section{Introduction}

Vancomycin is the most widely used antibiotic for preventing and treating methicillin-resistant Staphylococcus aureus (MRSA) infections [1]. Around two-thirds of the

Kannan Sridharan

skannandr@gmail.com

1 Department of Pharmacology and Therapeutics, College of Medicine and Medical Sciences, Arabian Gulf University, Manama, Bahrain

2 Department of Paediatrics, College of Medicine and Medical Sciences, Arabian Gulf University, Manama, Bahrain

3 Paediatric Intensive Care Unit, Salmaniya Medical Complex, Ministry of Health, Manama, Bahrain

\section{Key Points}

The current recommended vancomycin dose is ineffective in children admitted to the intensive care unit.

Lower therapeutic vancomycin levels are associated with increased risk of mortality in this sub-population.

A higher cumulative dose of vancomycin was associated with greater risk of acute kidney injury and the consequent risk of mortality. 
S. aureus isolates in the intensive care units (ICUs) are observed to be resistant to methicillin [2]. MRSA infections in the ICU are associated with increased morbidity, mortality and costs [3].

Standard treatment guidelines recommend maintaining trough levels of vancomycin between 10 and $20 \mathrm{mg} / \mathrm{L}$ [4]. The recommended trough levels are likely to ensure optimum bactericidal activity of vancomycin, based on the minimum inhibitory concentrations (MICs) for MRSA. Conflicting evidence exists on whether the MICs of MRSA for vancomycin have significantly increased over recent years $[5,6]$. Studies have reported a threefold increase in the risk of worsening of infections if the MICs for MRSA exceed $1.5 \mathrm{mg} / \mathrm{L}$ [7]. However, guidelines suggest maintaining a minimum trough level of $10 \mathrm{mg} / \mathrm{L}$ for vancomycin [8]. On the other hand, higher trough levels of vancomycin increase the risk of nephrotoxicity by two times [9]. The area under the time-concentration curve over $24 \mathrm{~h}\left(\mathrm{AUC}_{24}\right)$ is a better predictor for vancomycin's therapeutic effect, and trough levels are surrogate indicators for $\mathrm{AUC}_{24}$ [10]. However, therapeutic trough concentrations of vancomycin in the paediatric population have been argued to be significantly different from adults for achieving the desired $\mathrm{AUC}_{24}$ [11].

Pharmacokinetic parameters of several drugs have been observed to significantly change in patients admitted to the ICUs due to the critical nature of their disease [12]. Due to widespread systemic inflammation, patients may often have an augmented renal clearance (ARC) [13]. Increased volume of distribution and drug clearance were observed for vancomycin, resulting in sub-therapeutic trough levels of vancomycin [14]. This is further complicated in the paediatric age group because of different levels of organ function, depending on the age of the children [15]. Hence, unique challenges exist for dosing vancomycin in children admitted to ICUs. Although recommendations exist for appropriate levels to be maintained in the adult population, these are clearly lacking in children. In children, vancomycin has been dosed at $15 \mathrm{mg} / \mathrm{kg} / \mathrm{dose}$ as per the recommendations of the British National Formulary; however, a recent study from the UK observed that only $26 \%$ of children receiving this dose achieved the appropriate trough levels [16]. Recent studies from neonates admitted to ICUs and children with cancers corroborate the inadequate serum levels of vancomycin achieved with the recommended dosing strategies [17, 18]. Hence, we undertook the present study to assess the use of vancomycin and the corresponding trough levels in children admitted in the ICU of the largest tertiary care public hospital in Bahrain.

\section{Methods}

\subsection{Study Population and Study Ethics}

Children admitted in the ICU of Salmaniya Medical Complex, Manama, Bahrain who were administered vancomycin between January 2016 and March 2019 were included if at least one serum sample was assessed for therapeutic drug monitoring of vancomycin. Patients with incomplete details relating to drug administration were excluded. Approval from the local ethics committees and the Ministry of Health was obtained prior to the study being conducted. The study was carried out in compliance with the Declaration of Helsinki. The following details were captured for each eligible child: demographic factors (age, gender and body weight); diagnoses; duration of hospital stay; vancomycin-related details (dose, frequency and duration); serum vancomycin levels, blood urea and serum creatinine; concomitant drugs; and outcome (dead/alive). Steady state was considered to have been reached after three doses of vancomycin [19]. Creatinine clearance was assessed using the Shull equation that is specific for the paediatric population [20]. We used the Kidney Disease Improving Global Outcomes (KDIGO) clinical practice guidelines to assess the incidence of acute kidney injury (AKI) based only on the serum creatinine criteria [21]. Children were considered to have ARC if their estimated glomerular filtration rate (eGFR) was $\geq 20 \%$ the upper limit for their age [22]. The reference range is adapted from the results following a single injection of Tc-99 m diethylene triamine penta acetate (DTPA) [23], based on which the following are the upper limits of eGFR $\left(\mathrm{mL} / \mathrm{min} / 1.73 \mathrm{~m}^{2}\right)$ considered for defining ARC: $<1$ year, above $287 ; 1-2.5$ years, above $277.2 ;>2.5-5$ years, above $350.4 ;>5-10$ years, above $301.4 ;>10-15$ years, above 264 ; and $>15$ years, above 247.2. Children with renal dysfunction were analysed as a separate group. Only drugs for which predominant renal elimination or nephrotoxicity has been documented as a common adverse effect, such as aminoglycosides (gentamicin/amikacin), acyclovir and non-steroidal anti-inflammatory drugs (NSAIDs) (paracetamol and ibuprofen), were considered in this study. Use of vancomycin was considered empirical when the therapy was initiated, within $72 \mathrm{~h}$ of admission in the ICU or pending microbiological culture reports, whereas it was considered definitive if the therapy was initiated following appropriate microbiological culture reports [24]. The prescribed daily dose (PDD) was calculated as the average dose prescribed per day [25]. The World Health Organization-Uppsala Monitoring Centre (WHO-UMC) probability scale was used to assess the causal relationship of AKI with vancomycin use [26]. 


\subsection{Statistical Analysis}

Descriptive statistics were used to represent the demographic details. Distribution of the numerical data was assessed using the Kolmogorov-Smirnov test, and accordingly, they were described using mean [standard deviation (SD)] or median (range). The Kruskal-Wallis $H$ test was used to assess the initial dose of vancomycin per kilogram of body weight. Multivariable logistic regression analysis was used to assess the factors determining adequate trough levels in the study population. Although most of the guidelines recommend trough levels $10-20 \mathrm{mg} / \mathrm{L}$, some suggest maintaining between 5 and $15 \mathrm{mg} / \mathrm{L}$ for suspected mild infections [4]. Hence, we carried out logistic regression analyses for both these categories. The dependant factor was the serum vancomycin trough levels, and the independent factors were age, body weight, gender, creatinine clearance, dosing intervals, number of concomitant drugs ( $\leq 3$ or $>3$ ) that are either nephrotoxic or undergoing predominant renal elimination, and whether vancomycin was administered as an empirical or definitive therapy. A scatter plot between the predicted probabilities of AKI with the number of concomitant drugs with nephrotoxic potential was developed following the logistic regression. The diagnoses were grouped based on the organ systems, and the variable on the concomitant drugs was categorical (yes/no). Sub-group analyses were carried out for the following age groups: 1-12 months (infants); toddler (13-24 months); young children (2-5 years); and older children (above 6 years) [27]. Additional analyses were done for patients with renal dysfunction and outcome status (dead/ alive). Trend analyses for absolute and percentage changes in the serum creatinine were assessed using the Mann-Kendall test, and the Chi-square test was used for trend analysis for the categorical variables. Association of categorical variables was tested with Chi-square, and where appropriate, the Fisher-exact probability test was employed. A $P$ value of $\leq 0.05$ was considered significant.

\section{Results}

\subsection{Demographic Details}

Four-hundred and eighty children were admitted during the study period, of whom 146 were tested for serum vancomycin levels. Details of the concomitant medications and time of administration of vancomycin were not available for 44 children. Data from 102 children were included in the final analysis, of which 13 had renal dysfunction. The baseline characteristics of the participants are summarized in Table 1. The following were the diagnoses amongst the study participants: cystic fibrosis with acute exacerbation $(n=4)$; bronchiolitis $(n=8)$; cerebral palsy with or without
Table 1 Baseline characteristics of the study participants $(N=102)$

\begin{tabular}{lll}
\hline Characteristics & \multicolumn{2}{c}{ Parameter value } \\
\hline \multicolumn{2}{l}{ Patients without any renal impairment $(n=89)$} & \\
Age (years), n (\%) & Overall $^{\mathrm{a}}$ & $1.7(0.03-17)$ \\
& $\leq 1$ & $40(44.9)$ \\
& $>1-2$ & $11(12.4)$ \\
& $>2-5$ & $10(11.2)$ \\
& $\geq 5$ & $28(31.5)$ \\
Male:female $(n: n)$ & & $42: 47$ \\
Alive:died $(n: n)$ & & $79: 10$ \\
Body weight $(\mathrm{kg})^{\mathrm{b}}$ & & $14.1(13.5)$ \\
Patients with renal impairment $(n=13)$ & \\
Age (years), n & Overall ${ }^{\mathrm{a}}$ & $4(0.04-13)$ \\
& $\leq 1$ & 4 \\
& $>1-2$ & 1 \\
& $>2-5$ & 1 \\
Male:female $(n: n)$ & & 7 \\
Alive:died $(n: n)$ & & $10: 3$ \\
Body weight $(\mathrm{kg})^{\mathrm{b}}$ & & $10: 3$ \\
\hline
\end{tabular}

${ }^{\mathrm{a}}$ Median (range)

${ }^{\mathrm{b}}$ Mean (standard deviation)

post-operative ventriculo-peritoneal shunt with shunt malfunction $(n=3)$; encephalitis/metabolic encephalopathy $(n=6)$; congenital heart disease with heart failure/pneumonia $(n=17)$; status epilepticus with tracheostomy $(n=2)$; status epilepticus on mechanical ventilator $(n=3)$; status epilepticus with aspiration pneumonia $(n=3)$; post-operative trachea-oesophageal fistula $(n=2)$; pneumothorax/bacterial tracheitis $(n=2)$; metabolic disorder on mechanical ventilator $(n=3)$; Guillain-Barre syndrome $(n=2)$; Prader-Willi syndrome with bacterial tracheitis $(n=1)$; severe hypothyroidism with cardiac failure $(n=1)$; cystic hygroma complicated by sepsis $(n=1)$; infantile spasm $(n=1)$; pleural effusion with lung abscess $(n=5)$; head injury with subdural/intraventricular hematoma $(n=2)$; oesophageal perforation due to acid battery ingestion $(n=1)$; severe cellulitis complicated by sepsis $(n=1)$; severe acute exacerbation of bronchial asthma $(n=3)$; Glanzmann's thrombasthenia with epistaxis $(n=1)$; severe sepsis $(n=7)$; vaso-occlusive crisis in sickle cell disease $(n=3)$; post-operative repair of congenital heart disease $(n=2)$; hydrocephalus with right posterior fossa excision $(n=1)$; post-operative drainage of para-pharyngeal/retro-pharyngeal abscess $(n=2)$; renal dysfunction (chronic kidney disease/acute renal failure) with sepsis/peritonitis/pneumonia $(n=13)$; bacterial pericarditis/ pericardial effusion $(n=1)$; and mitochondrial disease with pneumonia $(n=1)$. The following were the indications (as empirical/definitive) for initiating vancomycin in the study population: sepsis $(n=18)$; ventilator-associated pneumonia 
$(n=2)$; meningitis/encephalitis $(n=4)$; post-operative cases

$(n=7)$; and pneumonia $(n=71)$.

\subsection{In Patients Without Any Renal Dysfunction}

\subsubsection{Vancomycin Regimen and Serum Trough Concentrations}

Vancomycin was administered intravenously in all the patients at an average (SD) dose (mg/dose) of 13 (3.9). The mean (SD) of initial dose in the study population was 12 (4) $\mathrm{mg} / \mathrm{kg}$, and the following was observed for the individual sub-groups: $\leq 1$ year, $12.5(3.2) ;>1-2$ years, 11.4 (3.8); $>2-5$ years, 13 (4.2); and $>5$ years, 11.2 (3.8). The differences in the initial vancomycin dose between the age groups were not statistically significant $(P>0.05)$. The median (range) duration (in days) of vancomycin administration was 5.5 (1-67). The median (range) cumulative dose (mg) of vancomycin administered to the participants was 1500 (60-19,500). Overall, the PDD (mg) was estimated to be 386.7 (338.5), and in the sub-groups of age it was as follows: $\leq 1$ year, 181.6 (153.1); 1-2 years, 227.8 (120.1); > 2-5 years, 463.2 (165.3); and > 5 years, 692.1 (377.7).

Two-hundred and fifty-two serum trough levels were checked. The median (range) for vancomycin concentration (mg/L) was 7.3 (0.6-44.5). The median (range) for vancomycin dose (mg) administered before the assessment of serum trough levels was 125 (15-750). One-hundred and three out of the total $252(40.9 \%)$ levels ranged between 5 and $10 \mathrm{mg} / \mathrm{L} ; 75$ (29.8\%) were less than $5 \mathrm{mg} / \mathrm{L} ; 63(25 \%)$ were between 10 and $20 \mathrm{mg} / \mathrm{L}$; and 11 (4.3\%) were above $20 \mathrm{mg} / \mathrm{L}$. No significant association was noted between age groups and attaining the recommended serum trough levels of vancomycin (Table 2). Of the 252 sample timepoints, $22(8.7 \%)$ received vancomycin twice a day; $119(47.2 \%)$ received it thrice daily; and $111(44 \%)$ received it four times daily. No significant association was observed between the frequency of administration and vancomycin trough levels. The median (range) of vancomycin doses before the assessment of serum trough levels was five (1-123). The median (range) time of the trough samplings from drug administration was 8.5 (1-48) h. Similarly, median (range) time of trough samplings from the initiation of vancomycin was 48 (4-672) h. Two-hundred and thirty samples were carried out when vancomycin was administered empirically and 22 when it was administered as definitive therapy. A significantly higher number of patients were observed with therapeutic trough levels of vancomycin with definitive therapy compared to empirical (Table 2), although this was in only $40.9 \%$ of the patients with proven infection. Also, a significantly lower number of serum samples were observed in the therapeutic range, along with a higher proportion above $20 \mathrm{mg} / \mathrm{L}$, amongst patients who died compared to alive patients (Table 2). Twenty-two samples were obtained for vancomycin concentrations following the first dose, while 186 were checked after steady state had been achieved. No significant differences were observed in the proportion of therapeutic versus sub- or supra-therapeutic range between single dose and steady state measurements (Table 2).

Table 2 Association of serum vancomycin levels with various parameters $[n(\%)]$

\begin{tabular}{|c|c|c|c|c|c|}
\hline \multirow[t]{2}{*}{ Parameters } & \multirow{2}{*}{$\begin{array}{l}\text { Groups (number of serum } \\
\text { trough levels) }\end{array}$} & \multicolumn{3}{|c|}{ Serum levels either at single dose or steady state } & \multirow[t]{2}{*}{$P$ value } \\
\hline & & $<10$ & $10-20$ & $>20$ & \\
\hline \multirow[t]{4}{*}{ Age (years) } & $\leq 1(117)$ & $78(66.7)$ & $33(28.2)$ & $6(5.1)$ & \multirow[t]{4}{*}{0.5} \\
\hline & $>1-2(27)$ & $21(77.8)$ & $6(22.2)$ & 0 & \\
\hline & $>2-5(31)$ & $23(74.2)$ & $8(25.8)$ & 0 & \\
\hline & $>5(77)$ & $57(74)$ & $15(19.5)$ & $5(6.5)$ & \\
\hline \multirow[t]{3}{*}{ Frequency of vancomycin } & Twice daily (22) & $14(63.6)$ & $6(27.3)$ & $2(9.1)$ & \multirow[t]{3}{*}{0.6} \\
\hline & Thrice daily (119) & $88(73.9)$ & $28(23.5)$ & $3(2.6)$ & \\
\hline & Four times daily (111) & $76(68.5)$ & $27(24.3)$ & $6(7.2)$ & \\
\hline \multirow[t]{2}{*}{ Type of vancomycin therapy } & Empirical (230) & $212(92.2)$ & $16(7)$ & $2(0.8)$ & \multirow[t]{2}{*}{$0.0001^{*}$} \\
\hline & Definitive (22) & $13(59.1)$ & $9(40.9)$ & 0 & \\
\hline \multirow[t]{2}{*}{ Outcome status } & Alive (191) & $62(32.4)$ & $127(66.5)$ & $2(1.1)$ & \multirow[t]{2}{*}{$0.0001^{*}$} \\
\hline & Dead (61) & $34(55.7)$ & $20(32.8)$ & $7(11.5)$ & \\
\hline \multirow[t]{2}{*}{ Renal clearance } & Normal $(n=244)$ & $171(70.1)$ & $62(25.4)$ & $11(4.5)$ & \multirow[t]{2}{*}{0.8} \\
\hline & Augmented $(n=8)$ & 7 & 1 & 0 & \\
\hline \multirow{2}{*}{$\begin{array}{l}\text { Timepoints of trough concentration } \\
\text { assessment }\end{array}$} & First dose $(n=22)$ & $17(77.3)$ & $5(22.7)$ & 0 & \multirow[t]{2}{*}{0.5} \\
\hline & Steady state $(n=186)$ & $128(68.8)$ & $44(23.7)$ & $11(7.5)$ & \\
\hline
\end{tabular}

*Statistically significant 


\subsubsection{Monitoring of Serum Creatinine During the Course of Vancomycin Therapy}

The mean $(\mathrm{SD})$ serum creatinine $(\mathrm{mg} / \mathrm{L})$ was $0.3(0.2)$, with a creatinine clearance $\left(\mathrm{mL} / \mathrm{min} / 1.73 \mathrm{~m}^{2}\right)$ of $127.3(72.7)$. Absolute and percentage changes in serum creatinine during vancomycin therapy are depicted in Figure $1 \mathrm{a}, \mathrm{b}$, and no significant trends were observed $(P>0.05)$.

Seven children showed elevation of serum creatinine more than 1.5-fold compared to baseline. The key characteristics of these patients with suspected AKI are listed in Table 3. All these adverse events could have possibly been related to vancomycin administration, as there were concomitant drugs that could also be attributed. Four out of the seven suspected AKI children died, while six out of 82 who did not develop any renal insufficiency died $(P=0.0025)$. The cumulative dose $(\mathrm{mg})$ of vancomycin for children with suspected AKI was 6059 (4724), while it was 2802 (3818) for the others $(P=0.034)$. In contrast, only one out of the seven suspected AKI children had trough levels ranging

\section{A Absolute changes in the serum creatinine}

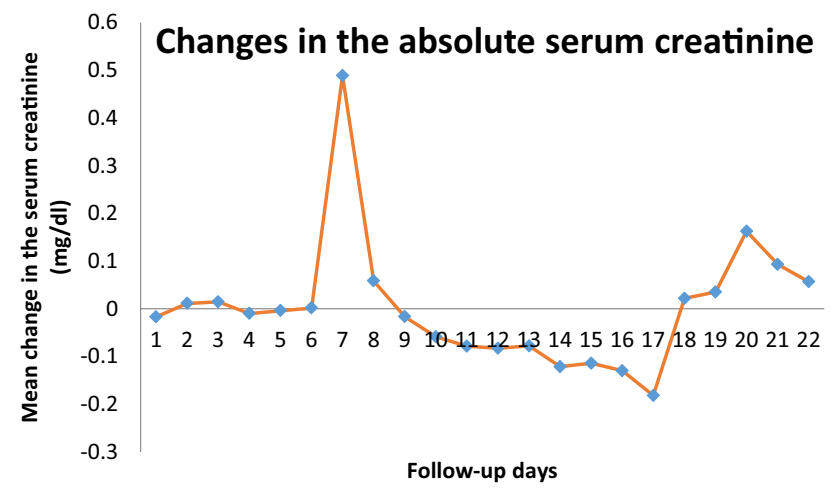

B Percent changes in the serum creatinine

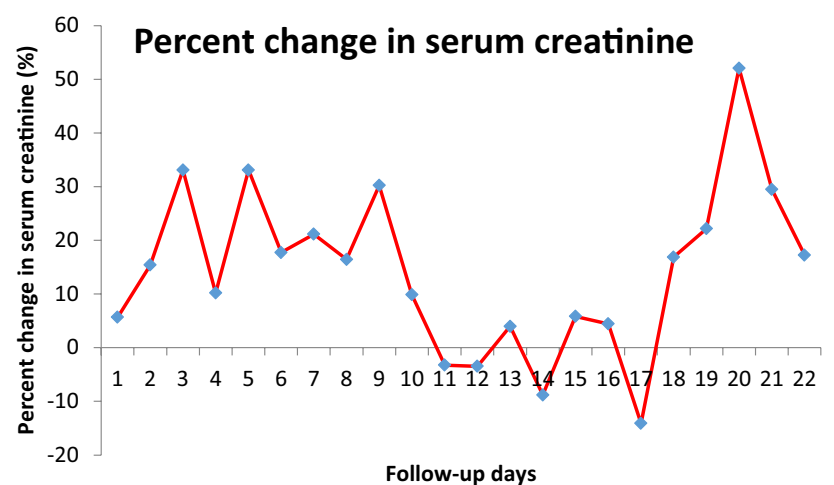

Fig. 1 Changes in the average serum creatinine during vancomycin therapy: a absolute changes in the serum creatinine; b percentage changes in the serum creatinine. No significant trends were observed in both the average absolute and percent changes in serum creatinine between 10 and $20 \mathrm{mg} / \mathrm{L}$, while 21 out of $82(25.6 \%)$ in the others had similar trough levels $(P=0.7)$.

Eight timepoints out of the total 253 were carried out on the days when patients had ARC. Six of these were observed in the age group of 5-10 years and the remaining in those between 10 and 15 years. Only one out of these eight had serum trough levels between 10 and $20 \mathrm{mg} / \mathrm{L}$. No statistically significant $(P=0.4)$ difference was observed in the proportion of timepoints with serum trough levels between 10 and $20 \mathrm{mg} / \mathrm{L}$ during the times of ARC compared to patients with normal renal clearance (Table 2).

\subsubsection{Concomitant Medications}

The median number (range) of concomitant drugs was 13 (5-45). Concomitant antimicrobials used along with vancomycin included gentamicin $(n=57)$, meropenem $(n=39)$, piperacillin/tazobactam $(n=37)$, cefotaxime $(n=15)$, clarithromycin $(n=13)$, ceftazidime $(n=13)$, metronidazole $(n=11)$, fluconazole $(n=10)$, clindamycin $(n=10)$, cefepime $(n=8)$, ceftriaxone $(n=8)$, amikacin $(n=6)$, acyclovir $(n=6)$, co-trimoxazole $(n=5)$, cloxacillin $(n=4)$, ampicillin $(n=4)$, ciprofloxacin $(n=2)$, caspofungin $(n=2)$, tigecycline $(n=2)$, azithromycin $(n=2)$, cefuroxime $(n=1)$, voriconazole $(n=1)$, ganciclovir $(n=1)$, levofloxacin $(n=1)$, and erythromycin $(n=1)$.

The median number (range) of concomitant drugs with potential nephrotoxicity/with predominant renal elimination was three (1-8). Such drugs included the following: gentamicin, piperacillin/tazobactam, acyclovir, fluconazole, amikacin, frusemide, cefepime, meropenem, paracetamol, cefotaxime, captopril, ceftriaxone, ganciclovir, ibuprofen, clindamycin, mannitol, acetazolamide, and cefuroxime. Patients with suspected AKI had a significantly higher number of such drugs compared to the others [5 (3-7) vs. 3 $(1-8) ; P=0.005]$. An increase in the number of concomitant drugs with nephrotoxic potential by one increases the odds of AKI by 1.7 [95\% confidence interval (CI) 1.1-2.5]. The scatter plot (Fig. 2) of the predicted probabilities of AKI revealed that the presence of more than five concomitant nephrotoxic drugs significantly increases the risk of AKI. However, no significant association was observed in the proportion of serum concentrations between 10 and $20 \mathrm{mg} / \mathrm{L}$ with the number of concomitant drugs that have potential nephrotoxicity or with predominant renal elimination $(P=0.2)$.

\subsubsection{Factors Determining the Serum Vancomycin Levels}

Logistic regression analysis revealed creatinine clearance as the only significant predictor for attaining the therapeutic serum levels of vancomycin in the range between 10 and $20 \mathrm{mg} / \mathrm{L}$ (Table 4). The overall accuracy of the model was 
Table 3 Characteristics of patients with acute kidney injury amongst children administered vancomycin

\begin{tabular}{|c|c|c|c|c|c|c|c|c|}
\hline \multicolumn{3}{|c|}{ Demographic features } & \multirow{2}{*}{$\begin{array}{l}\text { Concomitant } \\
\text { diseases }\end{array}$} & \multirow{2}{*}{$\begin{array}{l}\text { Cumulative } \\
\text { vancomycin dose } \\
(\mathrm{mg})\end{array}$} & \multirow{2}{*}{$\begin{array}{l}\text { Serum trough } \\
\text { levels }(\mathrm{mg} / \mathrm{L})\end{array}$} & \multirow{2}{*}{$\begin{array}{l}\text { Maximum percent- } \\
\text { age change in } \\
\text { serum creatinine }\end{array}$} & \multirow[t]{2}{*}{ Dead/alive } & \multirow[t]{2}{*}{ Concomitant drugs } \\
\hline Age (years) & Gender & $\begin{array}{l}\text { Body } \\
\text { weight } \\
(\mathrm{kg})\end{array}$ & & & & & & \\
\hline 1.5 & $\mathrm{~F}$ & 8 & TOF/VSD & 320 & 1.1 & 182.8 & Alive & $\begin{array}{l}\text { Frusemide, } \\
\text { gentamicin, aceta- } \\
\text { zolamide }\end{array}$ \\
\hline 0.33 & M & 9.3 & Acute bronchiolitis & 5454 & 1.3 & 188.9 & Alive & $\begin{array}{l}\text { Frusemide, } \\
\text { gentamicin, } \\
\text { acetazolamide, } \\
\text { piperacillin }\end{array}$ \\
\hline 8 & M & 25 & $\begin{array}{l}\text { AFP/encephalomy- } \\
\text { elitis }\end{array}$ & 1700 & 12.2 & 464.7 & Alive & $\begin{array}{l}\text { Frusemide, ceftri- } \\
\text { axone, acyclovir, } \\
\text { paracetamol }\end{array}$ \\
\hline 4 & $\mathrm{~F}$ & 13 & $\begin{array}{l}\text { Mitochondrial } \\
\text { disease }\end{array}$ & 6240 & 5.8 & 288.9 & Dead & $\begin{array}{l}\text { Gentamicin, flucon- } \\
\text { azole, acetazola- } \\
\text { mide, cefepime, } \\
\text { ciprofloxacin, } \\
\text { frusemide, pipera- } \\
\text { cillin }\end{array}$ \\
\hline 0.25 & M & 4.2 & Acute bronchiolitis & 14700 & 2.3 & 981.6 & Dead & $\begin{array}{l}\text { Gentamicin, flu- } \\
\text { conazole, pipera- } \\
\text { cillin, frusemide, } \\
\text { amikacin }\end{array}$ \\
\hline 1 & M & 8.3 & $\begin{array}{l}\text { Refractory status } \\
\text { epilepticus }\end{array}$ & 8600 & 7.8 & 150 & Dead & $\begin{array}{l}\text { Gentamicin, fru- } \\
\text { semide, piperacil- } \\
\text { lin, acyclovir, } \\
\text { meropenem, ami- } \\
\text { kacin, ganciclovir }\end{array}$ \\
\hline 0.5 & $\mathrm{~F}$ & 6 & $\begin{array}{l}\text { Guillian-Barre } \\
\text { syndrome }\end{array}$ & 5400 & 2.8 & 400 & Dead & $\begin{array}{l}\text { Fluconazole, gen- } \\
\text { tamicin, frusem- } \\
\text { ide, paracetamol }\end{array}$ \\
\hline
\end{tabular}

Concomitant drugs considered here include those with nephrotoxic potential or with predominant renal elimination

AFP acute flaccid paralysis, $F$ female, $M$ male, TOF tetralogy of Fallot, VSD ventral septal defect, WHO World Health Organization

Fig. 2 Scatterplot between the predicted probabilities of acute kidney injury (AKI) and the number of concomitant drugs with nephrotoxic potential. The probability of AKI significantly increases with more than five concomitant drugs with nephrotoxic potential

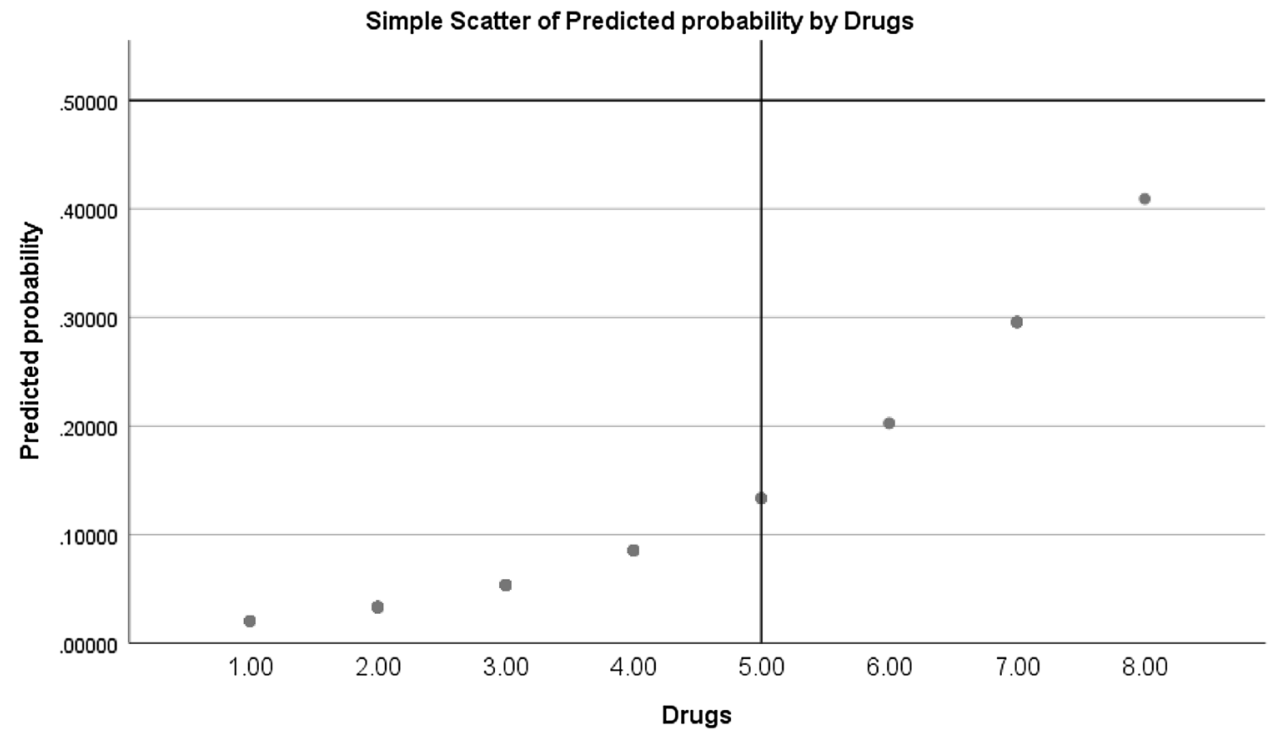


Table 4 Logistic regression analyses for predicting the recommended vancomycin trough levels

\begin{tabular}{|c|c|c|c|c|c|c|c|c|}
\hline \multirow[t]{2}{*}{ Parameters } & \multicolumn{4}{|c|}{ For serum trough levels between 10 and $20 \mathrm{mg} / \mathrm{L}$} & \multicolumn{4}{|c|}{$\begin{array}{l}\text { For serum trough levels between } 5 \text { and } \\
15 \mathrm{mg} / \mathrm{L}\end{array}$} \\
\hline & $B$ & Wald & $P$ value & OR $[95 \% \mathrm{CI}]$ & $\mathrm{B}$ & Wald & $P$ value & OR $[95 \% \mathrm{CI}]$ \\
\hline $\mathrm{Crcl}$ & -0.008 & 6.502 & $0.011^{*}$ & $0.99[0.99-0.99]$ & -0.001 & 0.593 & 0.441 & $0.99[0.99-1]$ \\
\hline Dose & 0.075 & 3.235 & 0.072 & $1.1[0.99-1.2]$ & 0.007 & 0.040 & 0.841 & $1.1[0.94-1.1]$ \\
\hline Body weight & -0.010 & 0.174 & 0.676 & $0.99[0.95-1.1]$ & 0.028 & 1.664 & 0.197 & $1.1[1-1.1]$ \\
\hline Age & -0.015 & 0.072 & 0.788 & $0.99[0.88-1.1]$ & 0.025 & 0.254 & 0.615 & $1.1[0.9-1.1]$ \\
\hline Female gender & -0.563 & 2.847 & 0.092 & $0.57[0.3-1.1]$ & -0.257 & 0.823 & 0.364 & $0.8[0.45-1.3]$ \\
\hline Frequency & & 0.739 & 0.691 & & & 0.057 & 0.972 & \\
\hline Thrice daily frequency & -0.115 & 0.042 & 0.838 & $0.9[0.3-2.7]$ & 0.031 & 0.004 & 0.951 & $1.1[0.4-2.8]$ \\
\hline Four times daily & -0.303 & 0.731 & 0.393 & $0.74[0.4-1.5]$ & -0.062 & 0.040 & 0.841 & $0.9[0.5-1.7]$ \\
\hline Definitive therapy & -0.801 & 2.667 & 0.102 & $0.5[0.2-1.2]$ & 0.587 & 1.576 & 0.209 & $1.8[0.7-4.5]$ \\
\hline $\begin{array}{l}\text { Concomitant drugs with potential nephro- } \\
\text { toxicity/predominant renal elimina- } \\
\text { tion }>3\end{array}$ & 0.100 & 0.097 & 0.755 & $1.1[0.6-2.1]$ & 0.116 & 0.177 & 0.674 & $1.1[0.7-1.9]$ \\
\hline Constant & 0.099 & 0.012 & 0.914 & 1.104 & -0.406 & 0.249 & 0.618 & 0.666 \\
\hline
\end{tabular}

$C I$ confidence interval, $\mathrm{Crcl}$ creatinine clearance, $\mathrm{OR}$ odds ratio

* Statistically significant

$76.2 \%$, with a good model fit as indicated by the Hosmer and Lemeshow test $(P=0.769)$. Similarly, accuracy of the model prediction was $58.3 \%$, and a good fit $(P=0.281)$ was observed for therapeutic serum levels of vancomycin of $5-15 \mathrm{mg} / \mathrm{L}$; none of the variables were observed to significantly predict the vancomycin levels.

Serum trough levels of vancomycin were also observed to significantly predict the risk of mortality. The hazard ratio (HR) of death with serum levels of vancomycin either $<10 \mathrm{mg} / \mathrm{L}$ or $>20 \mathrm{mg} / \mathrm{L}$ was 1.1 (95\% CI $1-1.1$; $P=0.05)$. Similarly, a trend was observed when vancomycin levels were considered as a categorical variable (either in the recommended trough levels of $10-20 \mathrm{mg} / \mathrm{L}$ or not) with mortality $[\mathrm{HR}=0.6(95 \% \mathrm{CI} 0.3-1) ; P=0.09]$.

\subsection{Patients with Renal Dysfunction}

Thirteen children had renal dysfunction at the time of vancomycin initiation, and their baseline characteristics are mentioned in Table 1. The median (range) vancomycin dose (mg/ dose) administered in this sub-population was 100 (15-500) and the duration of administration was 2 (1-22) days. The median (range) cumulative vancomycin dose (mg) was 167.5 (30-3850). Thirty-six serum vancomycin concentrations were available and ranged between 0 and 38.7, with a median concentration of $7.4 \mathrm{mg} / \mathrm{L}$. All patients received vancomycin as an empirical therapy. The median (range) serum creatinine ( $\mu \mathrm{mol} / \mathrm{L}$ ) was 94.4 (50.7-723), and the mean (SD) creatinine clearance $\left(\mathrm{mL} / \mathrm{min} / 1.73 \mathrm{~m}^{2}\right)$ was 25.1 (14.9).

The median (range) number of concomitant drugs administered was 14 (7-37). Concomitant antimicrobials included the following: gentamicin $(n=6)$, meropenem $(n=3)$, piperacillin/tazobactam $(n=3)$, metronidazole $(n=1)$, and one each for fluconazole, acyclovir, ceftriaxone, amikacin, and cefepime. Similarly, median (range) number of concomitant drugs with nephrotoxic potential/predominant renal elimination was three (0-7).

\section{Discussion}

We carried out the present study to evaluate the use of vancomycin in children admitted in the ICU. One-hundred and two children were identified, of whom 13 had renal dysfunction. Two-hundred and fifty-two vancomycin trough levels were available, of which only $25 \%$ were observed in the recommended range (10-20 $\mathrm{mg} / \mathrm{L})$ amongst patients without any renal dysfunction and $22 \%$ were observed amongst patients with renal dysfunction. Even in patients receiving vancomycin as definitive therapy, only $40.9 \%$ achieved the recommended trough levels. Lower trough levels were associated with increased risk of mortality. Nearly $4 \%$ of the levels were above $20 \mathrm{mg} / \mathrm{L}$ (toxic range). Seven children were suspected to have AKI during the course of therapy where cumulative vancomycin dose and mortality rate was higher. Only one serum vancomycin level during ARC was observed in the recommended range. All the patients received at least one concomitant drug that had either nephrotoxic potential or predominant renal elimination, and a higher number of such drugs has been observed with an increased risk of AKI.

Dosing strategies of vancomycin need to be revisited immediately, particularly in children. Current dosing 
of vancomycin is $15 \mathrm{mg} / \mathrm{kg} /$ day three to four times a day (40-60 mg/kg/day). Studies from other parts of the world have similar conclusions [17, 28-33]. Chang et al. predicted a mean dose of $75(22) \mathrm{mg} / \mathrm{kg} /$ day in paediatric cancer patients with normal renal function for achieving the therapeutic trough vancomycin concentration [34]. $\mathrm{AUC}_{24}$ upon the MIC for MRSA is the best predictor for bactericidal activity of vancomycin [35]. In adults, it has been established that $\mathrm{AUC}_{24} / \mathrm{MIC}>400$ is optimum for treating MRSA [36]. In children, the same cut-off value may not be appropriate due to altered renal function compared to adults, particularly when admitted to the ICU, altering the $\mathrm{AUC}_{24}$ of vancomycin. Studies suggest an increase in the MIC for MRSA from 0.5 to $2 \mathrm{mg} / \mathrm{L}[36,37]$. With an MIC of less than $0.5 \mathrm{mg} / \mathrm{L}$, a $40 \mathrm{mg} / \mathrm{kg} /$ day dosage of vancomycin might be adequate; but when the MIC is around $1 \mathrm{mg} / \mathrm{L}$, the dosage has to be increased to $60 \mathrm{mg} / \mathrm{kg} / \mathrm{day}$; and even in the latter scenario, the dosage may be insufficient if the MIC is $2 \mathrm{mg} / \mathrm{L}$ [38]. Currently, there are no published reports from Bahrain for MIC of MRSA. Recent studies suggest estimating $\mathrm{AUC}_{24}$ and titrating the vancomycin regimen accordingly rather than only trough-based adjustments [39]. Assessment of $\mathrm{AUC}_{24}$ by a Bayesian approach using validated software from population-specific pharmacokinetic parameters was observed to be superior compared to manual assessment [40]. Validated user-friendly software is available that can be tailored to the needs of each hospital/unit for estimating the real-time parameters in the patients [41]. However, costeffectiveness studies are lacking that demonstrate the utility of the Bayesian approach over conventional methods in achieving therapeutic vancomycin concentrations. A recent study from the UK suggests an increase in the frequency of vancomycin administration to four instead of three times a day [42]. We did not observe any significant benefits with a 6-hourly regimen of vancomycin in the present study. On the other hand, the risk of $\mathrm{AKI}$ is higher with increased dosages of vancomycin. Vancomycin doses resulting in $\mathrm{AUC}_{24}$ above $563 \mathrm{mg} \bullet \mathrm{h} / \mathrm{L}$ significantly increase the risk of AKI [43]. This was also evident in the present study, where the cumulative vancomycin dose was significantly higher amongst patients with suspected AKI compared to others. We also observed that concomitant drugs with potential nephrotoxicity, such as meropenem, gentamicin, piperacillin, and frusemide, were significantly more commonly present amongst children with AKI as compared with others $[44,45]$. Critically ill children with initial higher vancomycin concentrations were observed with increased risk of AKI [46]. Hence, if the MIC is more than $1 \mathrm{mg} / \mathrm{L}$, it may be prudent to use alternative antibiotics such as linezolid, eravacycline, omadacycline, plazomicin, clindamycin, tedizolid, dalbavancin, and oritavancin [47]. Continuous infusion of vancomycin was observed to be superior in terms of efficacy and safety in several studies, and thus could serve as an alternative to intermittent administration of vancomycin [48-50]. Interestingly, only $20 \%$ of children admitted in the ICU with appropriate trough levels had adequate $\mathrm{AUC}_{24} / \mathrm{MIC}$ ratio in a study [51]. Hence, it is judicious to use $\mathrm{AUC}_{24} / \mathrm{MIC}$ ratio directly rather than depending on the serum trough level. Intervention by a multi-disciplinary team consisting of physicians, nurses, and pharmacists and constant dissemination of information on dosing strategies based on the severity of infections has been shown to dramatically improve the success rate of achieving appropriate vancomycin trough levels, shortening of the time to reach such levels, and a reduced incidence of toxicity [52]. Also, measurement of unbound vancomycin concentrations is a better indicator than total levels particularly in critically ill neonates and children, and where possible methods for estimating free concentrations have to be established and practised [53, 54]. However, a consensus on the therapeutic levels for free vancomycin is yet to be reached.

We observed a significant association between creatinine clearance and therapeutic vancomycin concentrations. A previous study with a high empirical vancomycin regimen has concluded that an increase of $10 \mathrm{~mL} / \mathrm{min} / 1.73 \mathrm{~m}^{2}$ in creatinine clearance increases the odds of sub-therapeutic vancomycin levels by $47 \%$ for $20 \mathrm{mg} / \mathrm{kg}$ and $18 \%$ for $15 \mathrm{mg} / \mathrm{kg}$ dosing regimens [55]. Children admitted in the ICUs often exhibit ARC [56]. A recent study has estimated that children older than 7.9 years exhibit ARC significantly more compared to younger age groups [57]. We observed eight children, with the median age of 7 years, exhibiting ARC, of which only one had therapeutic vancomycin levels. Limited sample size and the method of estimation of creatinine clearance would have had an impact on the prevalence of ARC assessed in this study. Studies suggest increasing the vancomycin dosage to $70-90 \mathrm{mg} / \mathrm{kg} / \mathrm{day}$ for achieving the desired therapeutic outcome, and this recommendation is more appropriate particularly in critically ill children with ARC [58].

\section{Conclusion}

This is the first study in the region that has assessed vancomycin use in children admitted to ICUs. Further, we have assessed the influence of various factors in achieving the desired trough levels for vancomycin as well as in each of the categories of children. The study is limited by the following: the severity of the critical illness and co-morbid diseases could not be scored; details regarding the urine output were unavailable; and the height of the children during their ICU admission was not recorded, which is the case in a large majority of hospitals in developing countries, due to which Shull's equation was used to assess the creatinine clearance. Nevertheless, we feel that the identified data and interpretation is generalizable to a similar population elsewhere. To 
conclude, we observed that the current vancomycin dosing strategy is less effective in achieving the recommended trough levels and the sub-therapeutic vancomycin levels are associated with an increased risk of mortality.

Acknowledgements We thank the Research Technical Support Team in the Ministry of Health, Bahrain, for their ethics approval for carrying out this study.

\section{Compliance with Ethical Standards}

Funding No funding was obtained.

Conflict of interest The authors, K. Sridharan, A. Al-Daylami, R. Ajjawi and H.A.M. Al Ajooz, do not have any conflicts of interest to declare.

\section{References}

1. Liu C, Bayer A, Cosgrove SE, Daum RS, Fridkin SK, Gorwitz RJ, Kaplan SL, Karchmer AW, Levine DP, Murray BE, Rybak MJ, Talan DA, Chambers HF, Infectious Diseases Society of America. Clinical practice guidelines by the Infectious Diseases Society of America for the treatment of methicillin-resistant Staphylococcus aureus infections in adults and children. Clin Infect Dis. 2011;52:e18-55.

2. Abad CL, Pulia MS, Krupp A, Safdar N. Reducing transmission of methicillin resistant Staphylococcus aureus and vancomycinresistant Enterococcus in the ICU-an update on prevention and infection control practices. JCOM. 2014;21:218-32.

3. Yao Z, Peng Y, Chen X. Healthcare associated infections of methicillin-resistant Staphylococcus aureus: a case-control-control study. PLoS One. 2015;10:e0140604.

4. Ye ZK, Li C, Zhai SD. Guidelines for therapeutic drug monitoring of vancomycin: a systematic review. PLoS One. 2014;9:e99044.

5. Maclayton DO, Suda KJ, Coval KA, York CB, Garey KW. Casecontrol study of the relationship between MRSA bacteremia with a vancomycin MIC of 2 microg/mL and risk factors, costs, and outcomes in inpatients undergoing hemodialysis. Clin Ther. 2006;28:1208-16.

6. Diaz R, Afreixo V, Ramalheira E, Rodrigues C, Gago B. Evaluation of vancomycin MIC creep in methicillin-resistant Staphylococcus aureus infections-a systematic review and meta-analysis. Clin Microbiol Infect. 2018;24:97-104.

7. van Hal SJ, Lodise TP, Paterson DL. The clinical significance of vancomycin minimum inhibitory concentration in Staphylococcus aureus infections: a systematic review and meta-analysis. Clin Infect Dis. 2012;54:755-71.

8. Rybak M, Lomaestro B, Rotschafer JC, et al. Therapeutic monitoring of vancomycin in adult patients: a consensus review of the American Society of Health-System Pharmacists, the Infectious Diseases Society of America, and the Society of Infectious Diseases Pharmacists. Am J Health Syst Pharm. 2009;66:887.

9. Tongsai S, Koomanachai P. The safety and efficacy of high versus low vancomycin trough levels in the treatment of patients with infections caused by methicillin-resistant Staphylococcus aureus: a meta-analysis. BMC Res Notes. 2016;9:455.

10. Patel K, Crumby AS, Maples HD. Balancing vancomycin efficacy and nephrotoxicity: should we be aiming for trough or AUC/MIC? Paediatr Drugs. 2015;17:97-103.
11. Tkachuk S, Collins K, Ensom MHH. The relationship between vancomycin trough concentrations and AUC/MIC ratios in pediatric patients: a qualitative systematic review. Paediatr Drugs. 2018;20:153-64.

12. Macedo RS, Onita JH, Wille MP, Furtado GH. Pharmacokinetics and pharmacodynamics of antimicrobial drugs in intensive care unit patients. Shock. 2013;39:24-8.

13. Jeurissen A, Sluyts I, Rutsaert R. A higher dose of vancomycin in continuous infusion is needed in critically ill patients. Int $\mathbf{J}$ Antimicrob Agents. 2011;37:75-7.

14. Hirai K, Ishii H, Shimoshikiryo T, et al. Augmented renal clearance in patients with febrile neutropenia is associated with increased risk for subtherapeutic concentrations of vancomycin. Ther Drug Monit. 2016;38:706-10.

15. Lu H, Rosenbaum S. Developmental pharmacokinetics in pediatric populations. J Pediatr Pharmacol Ther. 2014;19:262-76.

16. Starkey E, Wignell A. Vancomycin dose and drug monitoring in paediatrics. Arch Dis Childhood. 2011;96:A44-5.

17. Ringenberg T, Robinson C, Meyers R, Degnan L, Shah P, Siu $A$, et al. Achievement of therapeutic vancomycin trough serum concentrations with empiric dosing in neonatal intensive care unit patients. Pediatr Infect Dis J. 2015;34:742-7.

18. Seixas GT, Araujo OR, Silva DC, Arduini RG, Petrilli AS. Vancomycin therapeutic targets and nephrotoxicity in critically ill children with cancer. J Pediatr Hematol Oncol. 2016;38:e56-62.

19. The Royal Children's Hospital clinical practice guidelines for vancomycin. https://www.rch.org.au/clinicalguide/guideline_ index/Vancomycin/. Accessed 27 May 2019.

20. Shull BC, Haughey D, Koup JR, Baliah T, Li PK. A useful method for predicting creatinine clearance in children. Clin Chem. 1978;24:1167-9.

21. Kellum JA, Lameire N, KDIGO AKI Guideline Work Group. Diagnosis, evaluation, and management of acute kidney injury: a KDIGO summary (Part 1). Crit Care. 2013;17:204.

22. Betancourt N, Bar A, Cies J. Augmented renal clearance in the pediatric intensive care unit. Crit Care Med. 2018;46:p678.

23. Du L, Zukotynski K, Hsiao E, Zurakowski D, Treves ST, Grant F. Pediatric reference ranges for glomerular filtration rate determined by a single injection of Tc-99m DTPA. J Nucl Med. 2009;50:1375.

24. Camins BC, King MD, Wells JB, Googe HL, Patel M, Kourbatova EV, Blumberg HM. Impact of an antimicrobial utilization program on antimicrobial use at a large teaching hospital: a randomized controlled trial. Infect Control Hosp Epidemiol. 2009;30:931-8.

25. WHO Essential medicines and health products. https://www.who. int/medicines/regulation/medicines-safety/toolkit_ddd_more/en/. Accessed 16 Apr 2019.

26. Zaki SA. Adverse drug reaction and causality assessment scales. Lung India. 2011;28:152-3.

27. Williams K, Thomson D, Seto I, Contopoulos-Ioannidis DG, Ioannidis JP, Curtis S, Constantin E, Batmanabane G, Hartling L, Klassen T, StaR Child Health Group. Standard 6: age groups for pediatric trials. Pediatrics. 2012;129:S153-60.

28. Durham SH, Simmons ML, Mulherin DW, Foland JA. An evaluation of vancomycin dosing for complicated infections in pediatric patients. Hosp Pediatr. 2015;5:276-81.

29. Glover ML, Cole E, Wolfsdorf J. Vancomycin dosage requirements among pediatric intensive care unit patients with normal renal function. J Crit Care. 2000;15:1-4.

30. Chang CN, Lo WT, Chan MC, Wang CC. A retrospective study to estimate serum vancomycin trough concentrations in pediatric patients with current recommended dosing regimen. J Med Sci. 2018;38:275-9.

31. Orr H, Trone D, Elder J, Raj A. Assessment of initial vancomycin dosing in pediatric oncology patients. Children (Basel). 2017;4:79. 
32. Broome L, So TY. An evaluation of initial vancomycin dosing in infants, children, and adolescents. Int J Pediatr. 2011;2011:470364.

33. Eiland LS, English TM, Eiland EH 3rd. Assessment of vancomycin dosing and subsequent serum concentrations in pediatric patients. Ann Pharmacother. 2011;45:582-9.

34. Chang D, Liem L, Malogolowkin M. A prospective study of vancomycin pharmacokinetics and dosage requirements in pediatric cancer patients. Pediatr Infect Dis J. 1994;13:969-74.

35. Rybak MJ. The pharmacokinetic and pharmacodynamic properties of vancomycin. Clin Infect Dis. 2006;42:S35-9.

36. Yang CC, Sy CL, Huang YC, Shie SS, Shu JC, Hsieh PH, Hsiao $\mathrm{CH}$, Chen CJ. Risk factors of treatment failure and 30-day mortality in patients with bacteremia due to MRSA with reduced vancomycin susceptibility. Sci Rep. 2018;8:7868.

37. Wang G, Hindler JF, Ward KW, Bruckner DA. Increased vancomycin MICs for Staphylococcus aureus clinical isolates from a university hospital during a 5-year period. J Clin Microbiol. 2006;44:3883-6.

38. Frymoyer A, Hersh AL, Benet LZ, Guglielmo BJ. Current recommended dosing of vancomycin for children with invasive methicillin-resistant Staphylococcus aureus infections is inadequate. Pediatr Infect Dis J. 2009;28:398-402.

39. Neely MN, Kato L, Youn G, Kraler L, Bayard D, van Guilder M, Schumitzky A, Yamada W, Jones B, Minejima E. Prospective trial on the use of trough concentration versus area under the curve to determine therapeutic vancomycin dosing. Antimicrob Agents Chemother. 2018;62:e2042.

40. Biagi MJ, Butler DA, Wenzler E. AUC-based monitoring of vancomycin: closing the therapeutic window. J Appl Lab Med. 2019;3:743-6.

41. Pai MP, Neely M, Rodvold KA, Lodise TP. Innovative approaches to optimizing the delivery of vancomycin in individual patients. Adv Drug Deliv Rev. 2014;77:50-7.

42. Mohsin-Shaikh S, Lumb P. An audit of paediatric vancomycin dosing. Arch Dis Childhood. 2016;101:e2.

43. Chavada R, Ghosh N, Sandaradura I, Maley M, Van Hal SJ. Establishment of an AUC(0-24) threshold for nephrotoxicity is a step towards individualized vancomycin dosing for methicillinresistant Staphylococcus aureus bacteremia. Antimicrob Agents Chemother. 2017;61:e02535.

44. Hundeshagen G, Herndon DN, Capek KD, Branski LK, Voigt CD, Killion EA, Cambiaso-Daniel J, Sljivich M, De Crescenzo A, Mlcak RP, Kinsky MP, Finnerty CC, Norbury WB. Co-administration of vancomycin and piperacillin-tazobactam is associated with increased renal dysfunction in adult and pediatric burn patients. Crit Care. 2017;21:318.

45. Pazhayattil GS, Shirali AC. Drug-induced impairment of renal function. Int J Nephrol Renovasc Dis. 2014;7:457-68.

46. Fitzgerald JC, Zane NR, Himebauch AS, Reedy MD, Downes KJ, Topjian AA, Furth SL, Thomas NJ, Scheetz MH, Zuppa AF. Vancomycin prescribing and therapeutic drug monitoring in children with and without acute kidney injury after cardiac arrest. Paediatr Drugs. 2019;21:107-12.
47. Kumar K, Chopra S. New drugs for methicillin-resistant Staphylococcus aureus: an update. J Antimicrob Chemother. 2013;68:1465-70.

48. Hoegy D, Goutelle S, Garnier N, Rénard C, Faure-Conter C, Bergeron C, Bertrand Y, Bleyzac N. Continuous intravenous vancomycin in children with normal renal function hospitalized in hematology-oncology: prospective validation of a dosing regimen optimizing steady-state concentration. Fundam Clin Pharmacol. 2018;32:323-9.

49. Hurst AL, Baumgartner C, MacBrayne CE, Child J. Experience with continuous infusion vancomycin dosing in a large pediatric hospital. J Pediatric Infect Dis Soc. 2018. https://doi.org/10.1093/ jpids/piy032.

50. Genuini M, Oualha M, Bouazza N, Moulin F, Treluyer JM, Lesage F, Renolleau S, Benaboud S. Achievement of therapeutic vancomycin exposure with continuous infusion in critically ill children. Pediatr Crit Care Med. 2018;19:e263-9.

51. Hahn A, Frenck RW, Allen-Staat M, Zou Y, Vinks AA. Evaluation of target attainment of vancomycin area under the curve in children with methicillin-resistant Staphylococcus aureus bacteremia. Ther Drug Monit. 2015;37:619-25.

52. Miloslavsky M, et al. The impact of pediatric-specific vancomycin dosing guidelines: a quality improvement initiative. Pediatrics. 2017;139:e20162423.

53. Oyaert M, Spriet I, Allegaert K, Smits A, Vanstraelen K, Peersman N, Wauters J, Verhaegen J, Vermeersch P, Pauwels S. Factors impacting unbound vancomycin concentrations in different patient populations. Antimicrob Agents Chemother. 2015;59:7073-9.

54. Smits A, Pauwels S, Oyaert M, Peersman N, Spriet I, Saegeman V, Allegaert K. Factors impacting unbound vancomycin concentrations in neonates and young infants. Eur J Clin Microbiol Infect Dis. 2018;37:1503-10.

55. Buckel WR, Ghobrial S, Tamma PD, Milstone AM, Zhao Y, Hsu AJ. Risk factors for non-therapeutic initial steady-state vancomycin trough concentrations in children and adolescents receiving high empiric doses of intravenous vancomycin. Paediatr Drugs. 2017;19:43-51.

56. Bauters T, Moerloose BD, Raes A, Schelstratete P, Dhooge C, Bordon V, Laureys G. Augmented renal clearance associated with vancomycin clearance in pediatric hemato-oncology and stem cell transplantation patients. Biol Blood Marrow Transplant. 2019;25:S275-6.

57. Avedissian SN, Bradley E, Zhang D, Bradley JS, Nazer LH, Tran TM, Nguyen A, Le J. Augmented renal clearance using population-based pharmacokinetic modeling in critically ill pediatric patients. Pediatr Crit Care Med. 2017;18:e388-94.

58. Rainkie D, Ensom MH, Carr R. Pediatric assessment of vancomycin empiric dosing (PAVED): a retrospective review. Paediatr Drugs. 2015;17:245-53. 